\title{
TO STUDY THE INTERRELATIONSHIP OF COPD ASSESSMENT TEST (CAT) SCORE WITH BODE INDEX AND SGRQ IN PATIENTS OF COPD
}

\author{
Shikhar Tripathi' ${ }^{1}$ Abhishek Srivastava ${ }^{2}$, S. S. Gupta 3 , A. Agarwal', A. Verma ${ }^{5}$, Amit Srivastava 6
}

${ }^{1}$ Assistant Professor, Department of Pulmonary Medicine, TSM Medical College, Lucknow.

${ }^{2}$ Associate Professor, Department of Pulmonary Medicine, Mayo Institute of Medical Sciences, Barabanki, U. P.

${ }^{3}$ Associate Professor, Department of Pulmonary Medicine, Era Lucknow Medical College and Hospital, Lucknow

${ }^{4}$ Assistant Professor, Department of Pulmonary Medicine, Era Lucknow Medical College and Hospital, Lucknow.

${ }_{5}^{5}$ Senior Resident, Department of Pulmonary Medicine, Era Lucknow Medical College and Hospital, Lucknow.

${ }^{6}$ Assistant Professor, Department of Pulmonary Medicine, Mayo Institute of Medical Sciences, Barabanki, U. P.

ABSTRACT

\section{BACKGROUND}

The objective of this study is to study the interrelationship of CAT score with BODE index and SGRQ in patients of COPD.

\section{MATERIALS AND METHODS}

All the patients attending the OPD within the study period with history of breathlessness on exertion were evaluated. The Hindi Version of SGRQ and CAT (COPD assessment test) questionnaire were being filled up by the patients in the study group. Patients were also grouped into four groups according to GOLD guideline. BODE index score was calculated by using FEV1, mMRC, BMI and 6MWT. Total CAT score, SGRQ score and BODE Index score was calculated and data analysed using various statistical tests.

\section{RESULTS}

Out of all the patients, total 90 patients of COPD were enrolled in the study. Among these, the mean age of the patients were 61.52 \pm 6.4 (48 - 72) and $77(85.5 \%)$ were males. Mean duration of the disease was $5.90 \pm 2.1$, mean pack years was 25.79 \pm 9.5 , mean no. of years of smoking was $25.11 \pm 10.3$, mean hospitalisations (per last year) was $0.12 \pm 0.3$, mean BMI $\left(\mathrm{kg} / \mathrm{m}^{2}\right)$ was $19.59 \pm 1.9$, mean respiratory rate was $17.71 \pm 1.2$, mean FEV1\% post-bronchodilator was $60.38 \pm 19.1$, mean FEV1/FVC was 53.08 \pm 13.7 , mean mMRC was $1.57 \pm 0.8$ and mean $6 \mathrm{MWT}(\mathrm{m}) 341.92 \pm 55.1$. In the present study, mean BODE Index Score was $2.78 \pm 1.9$, mean CAT Score was $21.10 \pm 5.3$ and mean Total SGRQ Score was $40.98 \pm 15.3$. A significant association of different GOLD stages with BODE Index and CAT Score was observed $(\mathrm{p}<0.001)$. It was observed that increase in mMRC grade, BODE Index and decrease in 6MWT is associated with increased CAT score. FEV1 (\%) predicted had a negative correlation $(r=-0.579)$ with CAT score; the other indices like BODE Index $(r=0.578)$ and SGRQ Total Score $(r=0.566)$ were positively correlated with CAT scores. This association was found to be statistically significant $(p<0.001)$.

\section{CONCLUSION}

There is a high degree of correlation between CAT Score, BODE Index and SGRQ. Health status as measured by COPD assessment test score and SGRQ worsens with disease severity evaluated by the BODE Index. It highlights its importance as a complement in the evaluation of the true impact of COPD on patients' daily lives.

\section{KEYWORDS}

CAT Score, BODE Index, SGRQ Interrelationship.

HOW TO CITE THIS ARTICLE: Tripathi S, Srivastava A, Gupta SS, et al. To study the interrelationship of COPD assessment test (CAT) score with BODE index and SGRQ in patients of COPD. J. Evolution Med. Dent. Sci. 2017;6(19):1489-1493, D0I: 10.14260/Jemds/2017/326

\begin{tabular}{l} 
BACKGROUND \\
COPD is an umbrella term used to describe the progressive \\
lung diseases including emphysema and chronic bronchitis. It \\
is characterised by partially reversible chronic airway \\
obstruction.1-3 The chronic, progressive clinical course of \\
COPD is aggravated by exacerbations affecting quality of life \\
and lung function. COPD patients have poor Health Related \\
Quality of Life (HRQoL) ${ }^{4-6}$ due to their symptoms, diminished \\
physical performance and the use of medications. \\
\hline Financial or Other, Competing Interest: None. \\
Submission 10-02-2017, Peer Review 25-02-2017, \\
Acceptance 27-02-2017, Published 06-03-2017. \\
Corresponding Author: \\
Dr. Shikhar Tripathi, \\
Assistant Professor, \\
Department of Pulmonary Medicine, \\
TSM Medical College, Lucknow. \\
E-mail: drshikhartripathi@gmail.com \\
DOI: $10.14260 /$ jemds/2017/326 \\
@C) 9 (1)
\end{tabular}

For initial evaluation proper treatment and regular followup of these patients, there is a need for stratification of severity of disease, which can be performed using simple clinical and physiological tools at the primary health care level itself. ${ }^{8}$ However, these measurements, when used as indices of functional damage or improvement correlate poorly with self-reported impairment of physical function or overall health status (quality of life), and hence provide an incomplete picture of impaired health. ${ }^{7}$ Chronic obstructive pulmonary disease is multisystem disorder and affects all aspects of life including work and home life, physical and sexual aspects of marriage, internal emotional factors and dependency needs. ${ }^{1}$

The health status of patients with Chronic Obstructive Pulmonary Disease (COPD) ${ }^{9}$ is currently being assessed using several different questionnaires. One of them is the COPD Assessment Test (CAT), which is a quick and easy test for patients to complete and provides a score that indicates the 
impact of the disease on their health status. This is a multidimensional 10-point scale which integrates body mass index, degree of airflow obstruction (FEV1 - Forced Expiratory Volume in 1 second) and dyspnoea by mMRC grading and exercise capacity measured in 6-min walk test.10 The higher scores in BODE index indicate a higher risk of death. The BODE index was designed to show that it is important to consider a range of factors rather than just a single component in the course of comprehensive assessment of COPD patients. ${ }^{10,11}$

The St. George's Respiratory Questionnaire (SGRQ) is a disease specific quality of life instrument designed to assess the quality of life of patients with COPD.12 The SGRQ score has also been shown to have an association with increased Health Care Resource Utilisation (HCRU) ${ }^{13}$ and with decreased survival. ${ }^{14}$ SGRQ is also responsive to pharmacological and non-pharmacological interventions. Some studies suggest a relationship between BODE index and SGRQ, but the studies have included a limited number of patients with short followup and none has explored the relative value of either tests to predict survival.

In the light of these facts, the present study was planned to study the interrelationship of CAT with BODE index and SGRQ in COPD patients.

\section{MATERIALS AND METHODS}

This prospective observational study was carried out in the patients attending the OPD of Department of Pulmonary Medicine, Mayo Institute of Medical Sciences, Barabanki, UP. A total of 90 patients were enrolled in the present study over a period of one year beginning from May 2014 to April 2015.

\section{Diagnostic Criteria for COPD}

Diagnosis of COPD was previously established based on a combination of characteristic symptoms (chronic cough, expectoration and/or dyspnoea), suggestive findings on physical examination (hyperinflation, rhonchi) and documented airflow limitation on spirometry that was poorly reversible with bronchodilators in the presence of established risk factors (like tobacco smoking, domestic exposure to biomass fuel combustion or environmental tobacco smoke or occupational exposure to mineral dust).

\section{Inclusion Criteria}

1. COPD diagnosed as per Gold guidelines patients in stage I, II, III, IV.

2. Patients who have no COPD exacerbations over the preceding 6 weeks and willingness to undergo studyrelated testing that included spirometry and had documented airflow limitation on spirometry (as evidenced by a post-bronchodilator FEV1/VC ratio less than $70 \%$ ) at initial evaluation.

3. Patient should be in a stable state for 1 month.

4. Patients should have no comorbidity.

\section{Exclusion Criteria}

1. Patient having drop in saturation to $<90 \%$ on 6 -minute walk test.

2. Patient on long-term oxygen therapy.

3. Patient unable to perform 6 meter walk test (6-MWT) and Spirometry.
Pulmonary Function Tests were performed at least 12 hours after the withdrawal of inhaled bronchodilators among the study group.

The 6MWT (6-minute walk test) was simple test that requires a $100-\mathrm{ft}$ hallway, but no exercise equipment or advanced training for technicians. This test measures the distance that a patient can walk on a flat, hard surface in a period of 6 minutes (6MWT).

The Hindi version of the SGRQ questionnaire was administered to each patient. The questionnaire is designed to elicit a patient's own opinion about his/her health. Patients were requested to complete the questionnaire themselves without assistance, as correctly and as completely as they could and it was stressed that there were no right or wrong answers. Missing data was recorded as such. The SGRQ questionnaire comprises of 50 questions (with 76 weighted responses) covering three independent domains; symptom, activity and impact. Scores ranging from 0 to 100 are computed for each component and a total score (also ranging from 0 to 100) is calculated based on responses to all items. A higher SGRQ score (either component or total) represents a poorer Health Related Quality of Life (HRQoL).

Dyspnoea assessment was carried out using the MMRC scales. The MMRC is an ordinal five-point scale (grades 0 to IV) based on degrees of various physical activities that precipitate dyspnoea. Grade IV represents the most severe category.

The BODE Index score was individually calculated for each patient enrolled in the study. The BODE index comprises the Body Mass Index (BMI), percentage of the predicted FEV1, dyspnoea by the MMRC and 6-minute walk test (6MWT) as an exercise capacity component. Scores ranged from 0 (best status) to 3 (worst status) for FEV1, 6MWT and MMRC, and 0 or 1 for BMI.

Data were analysed using SPSS 20.0 (SPSS Inc., Chicago, IL) software package. Results were expressed as mean \pm standard deviation, unless otherwise stated. In order to evaluate the correlation between parametric variables, the Pearson's correlation coefficient was utilised; $p$ values $<0.05$ were considered statistically significant.

\section{RESULTS}

During the study period of one year a total of 90 patients, who fulfilled the inclusion criteria were enrolled for the study.

The mean age was $61.52 \pm 6.4$, the sex ratio (M: F) was 77:13. Disease duration, Smoking history (Pack year), No. of years of smoking, hospitalisation (Per last Year), BMI $\left(\mathrm{kg} / \mathrm{m}^{2}\right)$, Respiratory rate, FEV1 \% predicted were $5.90 \pm 2.1$, $25.79 \pm 9.5,25.11 \pm 10.3,0.12 \pm 0.3,19.59 \pm 1.9,17.71 \pm 1.2,60.38$ \pm 19.1 and FEV1/FVC, mMRC, 6 MWT (m), BODE index, $\mathrm{SPO}_{2}$ CAT Score and Total SGRQ score were $53.08 \pm 13.7,1.57 \pm$ $0.8,341.92 \pm 55.1,2.78 \pm 1.9,95.70 \pm 1.7,21.10 \pm 5.3$ and $40.98 \pm 15.3$ respectively.

\begin{tabular}{|c|c|}
\hline Demographic Data & $\mathbf{N}=\mathbf{9 0}$ \\
\hline Age (Year) & \\
\hline Sex (M:F) & $61.52 \pm 6.4(48-72)$ \\
\hline Disease duration (Years) $^{*}$ & $5.90 \pm 2.1(2-10)$ \\
\hline Smoking history (Pack Year) $^{*}$ & $25.79 \pm 9.5(0-38)$ \\
\hline No. of years of smoking $^{*}$ & $25.11 \pm 10.3(0-39)$ \\
\hline
\end{tabular}




\begin{tabular}{|c|c|}
\hline Hospitalisation (Per Last Year)* & $0.12 \pm 0.3(0-1)$ \\
\hline BMI $\left(\mathrm{kg} / \mathrm{m}^{2}\right)^{*}$ & $19.59 \pm 1.9(17.2-26.4)$ \\
\hline Respiratory rate* & $17.71 \pm 1.2(16-20)$ \\
\hline FEV1 \% post-bronchodilator* & $60.38 \pm 19.1(20-86)$ \\
\hline FEV1/FVC* & $53.08 \pm 13.7(28-69)$ \\
\hline mMRC* & $1.57 \pm 0.8(0-4)$ \\
\hline 6-MWT $(\mathrm{m})^{*}$ & $\begin{array}{c}341.92 \pm 55.1(150- \\
490)\end{array}$ \\
\hline BODE index* & $2.78 \pm 1.9(0-8)$ \\
\hline $\mathrm{SPO}_{2}{ }^{*}$ & $95.70 \pm 1.7(93-98)$ \\
\hline CAT Score* & $21.10 \pm 5.3(9-34)$ \\
\hline Total SGRQ Score & $\begin{array}{c}40.98 \pm 15.3(14.16- \\
78.20)\end{array}$ \\
\hline
\end{tabular}

*= value express as mean \pm standard deviation (Min-Max), \#= value express as $\mathrm{N}(\%), \mathrm{M}=$ Male, $\mathrm{F}=$ Female, $\mathrm{kg} / \mathrm{m}^{2}=$ kilogram per square meter, $\mathrm{m}=$ metre, $\mathrm{BMI}=$ Body Mass Index, FEV1 = Forced Expiratory Volume in the first second, $\mathrm{FVC}=$ Forced Vital Capacity, $\mathrm{mMRC}=$ Modified Medical Research Council Scale, 6MWT $=6$-Minute Walk Test, $\mathrm{SPO}_{2}=$ Saturation of Peripheral Oxygen.

Table no. 2 shows COPD GOLD Stage of studied patients in 4 stages. In Stage I (mild), the mean age was $63.15 \pm 6.6$ year, BODE index was $0.88 \pm 0.43$ and CAT score was $17.35 \pm 3.1$. In Stage II (moderate) the mean age was $60.44 \pm 6.1$ years, BODE index was $2.06 \pm 0.6$ and CAT score was $20.56 \pm 4$.9. In Stage III (severe) the mean age was 62.92, BODE index was $4.88 \pm 0.9$ and CAT score was $24.19 \pm 4.2$. Similarly, in Stage IV (very severe) the mean age was $56.50 \pm 10.1$ years, BODE index was $7.50 \pm 1.0$ and CAT score was $30.00 \pm 3.2$. On comparison of the patients among the four COPD GOLD stages, we observe that while there was no significant difference in the age. There $p$ value was highly significant in BODE index and CAT Score, $(\mathrm{p}<0.001)$.

\begin{tabular}{|c|c|c|c|c|c|}
\hline \multicolumn{7}{|c|}{ COPD GOLD Stage } \\
\hline & $\begin{array}{c}\text { Stage I } \\
\text { (Mild) }\end{array}$ & $\begin{array}{c}\text { Stage II } \\
\text { (Moderate) }\end{array}$ & $\begin{array}{c}\text { Stage III } \\
\text { (Severe) }\end{array}$ & $\begin{array}{c}\text { Stage IV } \\
\text { (Very } \\
\text { Severe) }\end{array}$ & $\begin{array}{c}\text { P- } \\
\text { value }\end{array}$ \\
\hline N & $\mathbf{2 6}$ & $\mathbf{3 4}$ & $\mathbf{2 6}$ & $\mathbf{4}$ & \\
\hline $\begin{array}{c}\text { Age } \\
\text { (Year) }\end{array}$ & $62.31 \pm 6.6$ & $60.44 \pm 6.1$ & $\begin{array}{c}62.92 \pm \\
5.7\end{array}$ & $\begin{array}{c}56.50 \pm \\
10.1\end{array}$ & 0.167 \\
\hline $\begin{array}{c}\text { BODE } \\
\text { Index }\end{array}$ & $0.88 \pm 0.43$ & $2.06 \pm 0.6$ & $4.88 \pm 0.9$ & $7.50 \pm 1.0$ & 0.001 \\
\hline $\begin{array}{c}\text { CAT } \\
\text { Score }\end{array}$ & $17.35 \pm 3.1$ & $20.56 \pm 4.9$ & $\begin{array}{c}24.19 \pm \\
4.2\end{array}$ & $30.00 \pm 3.2$ & $<$ \\
\cline { 1 - 3 } Table 2. Comparison of BODE Index and CAT Score with \\
COPD GOLD Stage (n = 90)
\end{tabular}

$\mathrm{P}<0.001=$ highly significant

Table no. 3 showing distribution of FEV1 \% postbronchodilator, mMRC scale, 6MWT (m), BODE index parameters with respect to CAT categories. A highly significant difference was observed in the values of all the above parameters among the patients of different CAT categories. $\mathrm{P}$ values in respect of all the aforesaid indices \{FEV1 \% post-bronchodilator, mMRC scale, 6-MWT (m) and BODE index $\}$ are therefore $<0.001$.

\begin{tabular}{|c|c|c|c|c|c|}
\hline \multicolumn{2}{|c|}{$\begin{array}{c}\text { CAT } \\
\text { Categories }\end{array}$} & $\mathbf{N}$ & $\begin{array}{l}\text { Mean } \pm \\
\text { Standard } \\
\text { Deviation }\end{array}$ & Range & $\begin{array}{c}P \\
\text { value }\end{array}$ \\
\hline \multirow{5}{*}{$\begin{array}{l}\mathrm{FEV}_{1} \% \\
\text { post-bron- } \\
\text { chodilator }\end{array}$} & Group 1 & 1 & $82.00 \pm 0.0$ & $(82-82)$ & \multirow{5}{*}{$\begin{array}{c}< \\
0.001\end{array}$} \\
\hline & \begin{tabular}{|l|} 
Group 2 \\
\end{tabular} & 57 & $69.58 \pm 14.8$ & $(34-86)$ & \\
\hline & \begin{tabular}{|l|} 
Group 3 \\
\end{tabular} & 26 & $43.58 \pm 12.5$ & $(20-69)$ & \\
\hline & \begin{tabular}{|l|} 
Group 4 \\
\end{tabular} & 6 & $42.17 \pm 18.8$ & $(26-66)$ & \\
\hline & Total & 90 & $60.38 \pm 19.1$ & $(20-86)$ & \\
\hline \multirow{5}{*}{ mMRC } & Group 1 & 1 & $0 \pm 0.0$ & & \multirow{5}{*}{$\begin{array}{c}< \\
0.001\end{array}$} \\
\hline & Group 2 & 57 & 1.23 & & \\
\hline & Group 3 & 26 & $2.15 \pm 0.7$ & $(1-4)$ & \\
\hline & \begin{tabular}{|l|} 
Group 4 \\
\end{tabular} & 6 & 2.50 & & \\
\hline & Total & 90 & 1.57 & & \\
\hline \multirow{5}{*}{$\begin{array}{c}\text { 6-MWT } \\
\text { (m) }\end{array}$} & Group 1 & 1 & 480 & $(480$ & \multirow{5}{*}{$\begin{array}{c}< \\
0.001\end{array}$} \\
\hline & Group 2 & 57 & $358.88 \pm 36.2$ & $(295$ & \\
\hline & Group 3 & 26 & $320.1 \mathrm{C}$ & $(180-390)$ & \\
\hline & Group 4 & 6 & 252.0 & $(150-375)$ & \\
\hline & Total & 90 & $341.92 \pm 55.1$ & $(150-490)$ & \\
\hline \multirow{5}{*}{ BODE Index } & Group 1 & 1 & $1 \pm 0.0$ & $(1-1)$ & \multirow{5}{*}{$\begin{array}{c}< \\
0.001\end{array}$} \\
\hline & \begin{tabular}{|l|} 
Group 2 \\
\end{tabular} & 57 & $1.82 \pm 1.3$ & $(0-6)$ & \\
\hline & \begin{tabular}{|l|} 
Group 3 \\
\end{tabular} & 26 & $4.46 \pm 1.7$ & $(2-8)$ & \\
\hline & \begin{tabular}{|l|} 
Group 4 \\
\end{tabular} & 6 & $4.83 \pm 2.714$ & $(1-8)$ & \\
\hline & Total & 90 & $2.78 \pm 1.9$ & $(0-8)$ & \\
\hline \multirow{5}{*}{$\begin{array}{l}\text { Total SGRQ } \\
\text { Score }\end{array}$} & Group 1 & 1 & $29.60 \pm 0.0$ & $\begin{array}{r}(29.60- \\
29.60) \\
\end{array}$ & \multirow{5}{*}{$\begin{array}{c}< \\
0.001\end{array}$} \\
\hline & Group 2 & 57 & $33.58 \pm 10.6$ & $\begin{array}{r}(14.16- \\
66.24) \\
\end{array}$ & \\
\hline & Group 3 & 26 & $54.09 \pm 12.3$ & $\begin{array}{c}28.00- \\
73.76) \\
\end{array}$ & \\
\hline & Group 4 & 6 & $56.32 \pm 17.5$ & $\begin{array}{r}35.56- \\
78.20) \\
\end{array}$ & \\
\hline & Total & 90 & $40.98 \pm 15.3$ & $\begin{array}{c}(14.16- \\
78.20)\end{array}$ & \\
\hline \multicolumn{6}{|c|}{$\begin{array}{c}\text { Table 3. Showing Distribution of FEV1 \% Post-Bronchodilator, } \\
\text { mMRC Scale, 6-MWT (m), BODE Index, Parameters with } \\
\text { Respect to CAT Categories }\end{array}$} \\
\hline
\end{tabular}

Group 1 = CAT score < 10 (Low); Group 2 = CAT score 10 - 20 (Medium); Group 3 = CAT score $21-30$ (High); Group 4 = CAT score $>30$ (Very High), $\mathrm{N}=$ sample size, $\mathrm{SD}=$ Standard Deviation, $<0.001=$ highly significant.

Table no. 4 shows the correlation between CAT score and various diagnostic parameters, whereas FEV1 (\%) postbronchodilator had a negative correlation $(r=-0.579)$ with CAT score, the other indices like BODE index $(r=0.578)$ and SGRQ total score $(r=0.566)$ were positively correlated with CAT scores. All parameters were highly correlated to CAT score, $(\mathrm{p}<0.001)$.

\begin{tabular}{|c|c|c|c|c|}
\hline \multicolumn{2}{|c|}{ Correlations } & $\begin{array}{c}\text { FEV1 (\%) Post- } \\
\text { bronchodilator }\end{array}$ & $\begin{array}{c}\text { BODE } \\
\text { Index }\end{array}$ & $\begin{array}{c}\text { SGRQ } \\
\text { Total } \\
\text { Score }\end{array}$ \\
\hline \multirow{3}{*}{$\begin{array}{c}\text { CAT } \\
\text { Score }\end{array}$} & $\begin{array}{c}\text { Pearson } \\
\text { (r) }\end{array}$ & $-0.579^{* *}$ & $0.578^{* *}$ & $0.566^{* *}$ \\
\cline { 2 - 5 } & P value & $<0.001$ & $<0.001$ & $<0.001$ \\
\cline { 2 - 5 } & N & 90 & 90 & 90 \\
\hline \multirow{4}{*}{ Table 4. Showing Correlation between Different Diagnostic } \\
Parameters \\
\hline
\end{tabular}

FEV1 $=$ Forced Expiratory Volume in the first second, ${ }^{* *}=$ Correlation is significant at the 0.01 level (2-tailed). *= Correlation is significant at the 0.05 level (2-tailed), $p<0.001$ $=$ highly significant. 


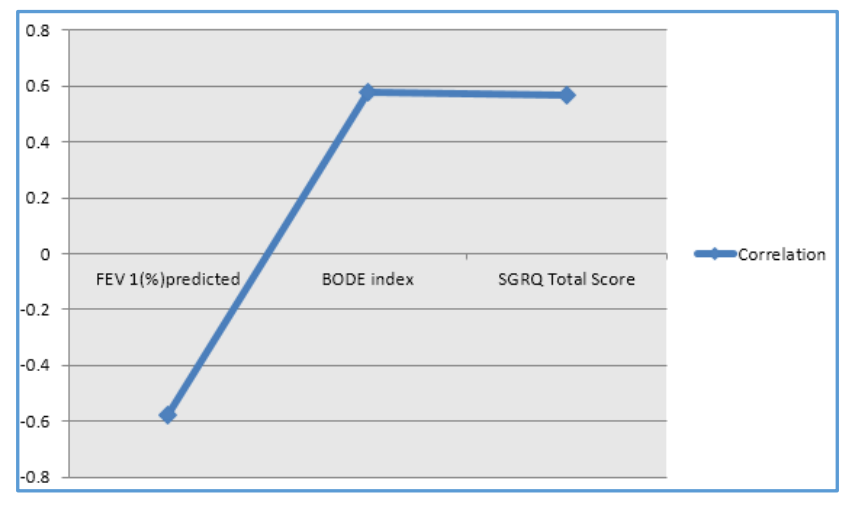

Line Graph showing Correlation between Different Diagnostic Parameters

\section{DISCUSSION}

COPD is a complex disease with multiple consequences including breathlessness, exercise limitation, muscle wasting, weight loss, increased hypercoagulability, depression, coronary artery disease and other systemic inflammatory effects. Although, the severity of airflow obstruction is evaluated by forced expiratory volume in one second (FEV1), PFT does not show the multidimensional effect of systemic inflammation on health status. ${ }^{10}$ This study was carried out to investigate the interrelationship between CAT score, BODE index and SGRQ.

In present study, the correlation between CAT score and BODE index was found significant association as $r=0.578$ and $\mathrm{p}<0.001$. Ladeira $\mathrm{I}$ et $\mathrm{al}^{15}$ was reported positive correlation between CAT score and BODE index as $\mathrm{R}=0.475$, $\mathrm{p}<0.001$.

Another study of $\mathrm{Gu} \mathrm{JH}$ et $\mathrm{al}^{10}$ was found to be positive correlated as $r=0.888$ and $p<0.001$. Further on comparison, the positive co-relations found with BODE index reinforce the discriminative validity of CAT as a complement in the evaluation of what the true impact of COPD is on a patient's daily life. CAT is relevant to BODE in evaluating incidence of exacerbation and mortality for patients with COPD and CAT is more easily to be applied.

Weight loss is one of the common systemic effects of COPD. In a retrospective study of 400 patients, Schols AM et al reported increased mortality in severe COPD patients with chronic hypoxaemia and a BMI $<25 \mathrm{~kg} / \mathrm{m} 2$. Another study showed a significant correlation between Fat Free Mass Index (FFMI) and MMRC, FEV1, FEV1/FVC. BMI and FFMI were found to be related to 6-MWT, but there was no correlation between BMI and disease severity. It was suggested that FFMI showed a better correlation with disease severity than BMI. 6-MWT utilisation has recently been increased in the evaluation of functional status and exercise performance of COPD patients. In our study similar to Marin's findings 6MWT was found correlated with MMRC, COPD stage according to GOLD and PFT parameters. There was also a significant relationship between 6-MWT and age, disease duration and annual hospitalisation rates.

In present study, we found positive correlation with Total SGRQ score ( $\mathrm{r}=0.566$ and $\mathrm{p}<0.001)$ as similarly to study done by Hwang YI et al ${ }^{16}$ reported that the CAT score was positively correlated with the SGRQ score $(\mathrm{r}=0.76, \mathrm{p}<$ 0.0001) and also with each component of SGRQ: symptoms, activity and impacts; $\mathrm{r}=0.68, \mathrm{r}=0.61$ and $\mathrm{r}=0.72$, respectively (all $\mathrm{p}<0.0001$ ). Another study also found positive correlation with SGRQ score $(\mathrm{r}=0.72, \mathrm{P}<.001)$ (Kwon $\mathrm{N}$ et $\mathrm{al}^{12}$ ). The CAT with a good sense of the health impact associated with different scores. More generally they provide a surprising insight into the severity of the effects of COPD, even in patients with apparently mild-moderate health status impact. In a study of COPD patients in which the relationship between BODE index and SGRQ was investigated, the BODE index was found to increase as SGRQ scores increased. There was a moderate and high relationship between CAT score and BODE; however, COPD stage according to GOLD had a mild correlation with SGRQ.

\section{CONCLUSION}

On the basis of observations made in the present study comparing the patients among the four COPD GOLD stages, we observed that there was no significant association with age. However, a significant association of different GOLD stages with BODE index and CAT score was observed ( $\mathrm{p}<$ 0.001 ). It was observed that increase in MMRC grade, BODE Index and decrease in 6-MWT is associated with increased CAT score. FEV1 (\%) predicted had a negative correlation $(\mathrm{r}=$ -0.579) with CAT score; the other indices like BODE index $(\mathrm{r}=$ $0.578)$ and SGRQ total score $(r=0.566)$ were positively correlated with CAT scores. This association was found to be statistically significant $(\mathrm{p}<0.001)$. These results provide users of the CAT with a good sense of the health impact associated with different scores. When the relation of these parameters with each other was investigated, a high degree of correlation was observed (Pearson correlation test). The correlation of CAT and BODE index was higher than others. It highlights its importance as a complement in the evaluation of the true impact of COPD on patients' daily lives.

\section{REFERENCES}

[1] The global initiative for chronic obstructive lung disease (GOLD), Global strategy for the diagnosis, management, and prevention of COPD, updated 2015. http://www.goldcopd.org.

[2] Jones PW, Prince M, Wijkstra PJ, et al. Quality of life in patients with chronic obstructive pulmonary disease. Eur Respir Mon 2006;38:375-86.

[3] Stahl E, Jansson SA, Svensson K, et al. Health - related quality of life utility and productivity outcomes instruments: ease of completion by subjects with COPD. Health Qual Life Outcomes 2003;1:18.

[4] Jindal SK, Gupta D, Aggarwal AN. Guidelines for management of chronic obstructive pulmonary disease (COPD) in India: a guide for physicians (2003). Indian J Chest Dis Allied Sci 2004;46(2):137-53.

[5] Curtis JR, Deyo RA, Hudson LD. Pulmonary rehabilitation in chronic respiratory insufficiency. 7. Health-related quality of life among patients with chronic obstructive pulmonary disease. Thorax 1994;49(2):162-70.

[6] Chetta A, Olivieri D. The COPD assessment test in the evaluation of chronic obstructive pulmonary disease exacerbations. Expert Rev Respir Med 2012;6(4): 373-5. 
[7] Jones PW, Quirk FH, Baveystock CM, et al. A selfcomplete measure of health status for chronic airflow limitation. The St George's respiratory questionnaire. Am Rev Respir Dis 1992;145(6):1321-7.

[8] Freeborne N, Lynn J, Desbiens NA. Insights about dying from the SUPPORT project. The study to understand prognoses and preferences for outcomes and risk of treatment. J Am Geriatr Soc 2000;48 (5 Suppl):S199-205.

[9] Watz H, Waschki B, Meyer T, et al. Physical activity in patients with COPD. Eur Respir J 2009;33(2):262-72.

[10] Gu JH, Qiu YJ, Lu YH, et al. Value of quality of life evaluation in prognosis of chronic obstructive pulmonary disease. Zhejiang Da Xue Xue Bao Yi Xue Ban 2014;43(2):207-11.

[11] Marin JM, Carrizo SJ, Gascon M, et al. Inspiratory capacity, dynamic hyperinflation, breathlessness, and exercise performance during the 6-minute-walk test in chronic obstructive pulmonary disease. Am J Respir Crit Care Med 2001;163(6):1395-9.
[12] Kwon N, Amin M, Hui DS, et al. Validity of the COPD assessment test translated into local languages for Asian patients. Chest 2013;143(3):703-10.

[13] Sarkar SK, Basuthakur S, Das SK, et al. Evaluation of correlation of BODE index with health-related quality of life among patients with stable COPD attending a tertiary care hospital. Lung India 2015;32(1):24-28.

[14] Ong KC, Lu SJ, Soh CS. Does the multidimensional grading system (BODE) correspond to differences in health status of patients with COPD? Int J Chron Obstruct Pulmon Dis 2006;1(1):91-6.

[15] Ladeira I, Gomes T, Castro A, et al. WITHDRAWN: the overall impact of COPD (CAT) and BODE index on COPD male patients: correlation? Rev Port Pneumol 2014;S0873-2159(14)00043-9.

[16] Hwang YI, Jung KS, Lim SY, et al. A Validation study for the Korean version of chronic obstructive pulmonary disease assessment test (CAT). Tuberc Respir Dis (Seoul) 2013;74(6):256-63. 